\title{
MJN \\ PREDICTORS IN THE COMMISSION OF ERRORS IN THE WARD AMONG STUDENT NURSES OF BUTUAN CITY
}

\section{Lovelyn A. Garcia}

Cebu Normal University, College of Nursing, Philippines

Corresponding Author’s Email: lovelyngtipon@gmail.com

\begin{abstract}
The study sought to determine the predictors in the commission of errors in the nursing procedure in the ward among Level IV nursing students of Father Saturnino Urios University. Utilizing a descriptive research design, student respondents were selected through the non-probability sampling employing the convenience sampling while complete enumeration was utilized in the choice of clinical instructors and staff nurses. Findings revealed that the respondents often have the knowledge and skills, and manifest favourable attitudes that are important in the application of nursing procedures so that errors in the ward be less committed. Correlation between the predictors and the errors committed in the ward as to admission and routine procedure revealed that there is a significant relationship between the commission of errors and the identified predictors. Due to the fact that they have different levels of education, experience and expectations, a significant difference in the ratings of the respondents on the commission of errors of nursing procedure in the ward was revealed. On the other hand, there is no significant difference in the ratings of the respondents on the commission of errors of nursing procedure in the ward for the routine procedures maybe because the respondents are already used to the varied procedural details. More knowledge, mastery of nursing skills in providing care to the patients and positive attitudes of the health personnel in the admission and routine procedures lead to less commission of errors in the ward.
\end{abstract}

Keywords: Commission of Errors, Competence, Knowledge, Skills, Attitude

\section{INTRODUCTION}

According to Catalano (1991) the patients under the care of a nurse are vulnerable by virtue of illness or injury. It is this dual-vulnerability that creates the nurse's duty to protect the patient. However, despite the utmost care in the observance of the basic procedures, nurses and student affiliates still commit errors. It has been observed that student affiliates commit errors in the clinical area particularly during admission and routine procedures.

Innumerable errors in the clinical area have been reported, ranging from minor errors to serious offences resulting in the deaths of the patients. One of the best examples is the Puerto Princesa's hospital who became the centre of controversy following the death of a patient after an erroneous blood transfusion (Ju, 2004). Another example happened last January 22, 2008 where in an incident in the Geriatric Ward of St. Luke's Medical Center came into light about the misuse of appropriate antibiotics leading to a septic and more deteriorated geriatric patient in the ward (Chance, 2008). Consequently, nurses should develop the necessary competence (knowledge, skills, and attitudes) to effectively render proper nursing services (James, Demaree \& Wolf, 1993). Apart from these cases, there are still numerous scenarios unreported. And, sad to say, that this situation was taken for granted by many. With the increasing incidence of error commission, the questions in the researcher's mind were: What are the causes of these errors? It is also for this reasons that researcher delved into this study to determine the predictors in the commission of errors on the nursing procedures. Nonetheless, this study will also serve as an 
eye opener to staff nurses, student nurses and clinical instructors in order for them to render the most suitable and quality care for their patients.

\section{LITERATURE REVIEW}

Nursing places the biggest role in all aspects of health care. This is the foremost reason why student nurses are being exposed and trained to the actual scenario in the ward. Hence, they are expected to have the knowledge and the skill to be able to perform the nursing care service. In terms of knowledge, nurses as contributing members of the society should assume responsibilities. Their nursing actions should be based on scientific knowledge and principles and should prioritize genuine concern for the client's welfare and interest.Learning is a life-long process of requiring the acquisition of everchanging knowledge, skills and attitude. Thus, student affiliates, nurses and clinical instructors should always enhance their skills and competencies through seminars, trainings, and continuing education to provide quality nursing care Potter et al., 1990 For the students, knowledge is required in order to have the scientific foundation in which their profession is based on, to acquire the important skills of the nursing profession (Robles \& Dionisio, 2001).

Attitude on the other hand is an emotional intelligence of a nurse that is crucial in the nursing process and practice of care. The elements of human caring, compassion, devotion, and commitment are crucial to the profession and are reciprocated by client satisfaction in what is often perceived as top-quality care. An individual, who manifests the desirable attitude, is observed to be more committed to service and to their patients as well. Providing that they are equipped with the knowledge and skills, thus malpractices, negligence and errorcommission in the ward is most likely prevented and minimized (James, Demaree \& Wolf, 1993).

According to Robles \& Dionisio, (2001) "Nurse has a nurturing ability and it is best evident in the caring for the patient upon the admission process. A nurse assist the patient in carrying out activities by the time the patient is being admitted in the hospitals, nurses may even have the abilities to receive the patient in the hospitals in the same courteous manner that they would use to welcome a guest in their own home." Apart from this, the nurse and student nurses are also held responsible of the patient's family to clearly explain the care, treatment or procedures rendered to the patient.

Shifts report is given to all nurses on the next shift to provide continuity of care to clients by providing the new caregivers a quick summary of client's needs and details of care to be given. It also allows the listener to ask questions during the endorsement. The nurse is expected to follow the particular order such as the following up of room number in the hospital which is necessary in providing the basic information for each client.

\section{Framework}

The study is anchored on the concept of Ernestine Weidenbach that describes the purpose of nursing to be facilitative of the efforts of the individual in overcoming the obstacles that constantly interfere with his/her ability to respond to the demands brought by the external environment. His theory believed that there were 4 main elements to clinical nursing. This includes: a philosophy, a purpose, a practice and the art (Chinn \& Jacobs, 1987).

The nurses' philosophy was their attitude and belief about life and how that affected reality for them. Philosophy is what motivates the nurse to act in a certain way (Marriner-Tomey \& Alligood, 2002). Nursing primarily consists of identifying a patient's need for help. If the need for help requires intervention, the nurse facilitates the medical plan of care and also creates and implements a nursing plan of care based on needs and desires of the patient. The patient's perception of the situation is an important consideration to the nurse when providing competent care (Sitzman \& Eichelberger, 2010).

To further explain this concept, this means that these nurses as the primary care giver of the patients, their primary goal of becoming well from ill should develop the commitments to serve. Being a nurse, it is their responsibility to free the patients from external harms and obstacles that may hinder their wellness status. Thus, these obstacles now are being referred to the errors committed in the nursing procedures in the ward setting. They require broad knowledge and accurate application of principles for the development of skills in order todeliver care effectively to the patient with utmost efficiency of work. Figure 1 shows the research paradigm of the study. 


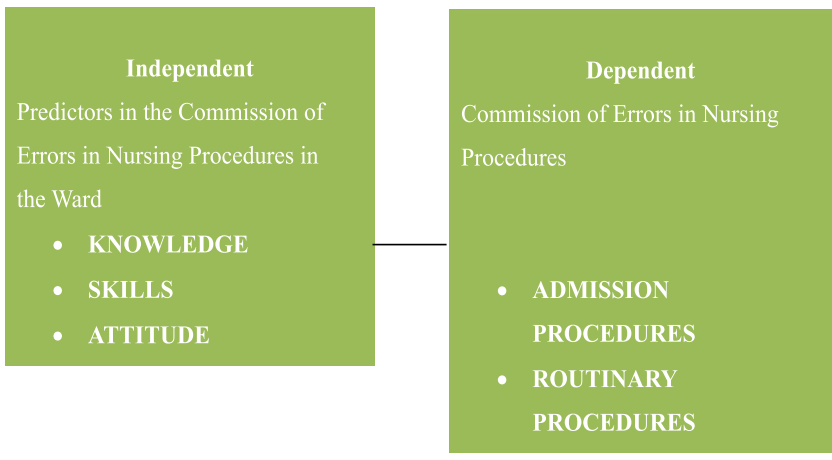

\section{Figure 1: The Research Paradigm}

Knowledge, skills and attitudes influence the performance of the health care team in the performance of the admission and routinely procedures. The study of $\mathrm{Ju}(2004)$ revealed that the attitude of the staff nurses and other health personnel are perceived to be stressprone in performing nursing tasks that led to the commission of errors.

\section{Statement of the Problem}

The study aimed to determine the predictors in the commission of errors in nursing procedure in the ward among the level IV students of Father Saturnino Urios University, Butuan City.

Specifically, it sought to answer on the following questions.

1. What are the predictors in the commission of errors of nursing procedure in the ward in terms of Knowledge, skills and attitude?

2. What are the errors committed in the nursing procedure in terms Admission and Routinely Procedure

3. Is there a significant relationship between the predictors in the commission of errors and the errors committed in the ward?

4. Is there a significant difference in the ratings of the respondents on the commission of errors of nursing procedure in the ward?

5. Which of the predictors in the commission of errors of nursing procedure will influence the commission of errors in the ward?

\section{Significance of the Study}

This study will help the administration gauged the effectiveness of their plans made for the enhancement of the nursing program thus, this will make the clinical instructors aware of their teaching style to guide the student nurses in providing quality nursing care without committing errors. Student nurses will realize on how to enhance their knowledge and skills in nursing care service and develop pleasant attitudes to minimize the incidence of committing errors not only in the wards but in all aspects of the nursing profession. Moreover, the patients who have been the client of this course are the ultimate beneficiaries of this study since the services rendered by the student nurses will be improved to provide them quality care thus providing them emphasis on their right to be protected from any harm in the health care system.

\section{RESEARCH METHODOLOGY}

The study used descriptive-co relational design.It was conducted at Father Saturnino Urios University, located at Butuan City. Specifically, it involves the nursing program. Sampling Technique utilized was non-probability utilizing the convenience sampling technique in the selection of the student respondents. A researcher-made instrument containing Part I which pertained to the predictors in the commission of errors in nursing procedure in the ward and Part II which contained items on the commission of errors in nursing procedure was utilized that was patterned from the ward evaluation tool of the program constructed in a simple way but comprehensive enough to allow the collection of information. Try out was done to justify its validity and reliability, result of pre-testing was analysed by the researcher's statistician with a reliability coefficient 0.97 which is considerably very high.

To facilitate null hypotheses testing, weighted mean has been used to determine the average rating of the predictors and to determine the rating of the errors committed. Pearson Product Moment Coefficient of Correlation was used to determine the significant relationship between the predictors and errors committed. One Way Analysis of Variance (ANOVA) was used to determine significant difference in the ratings of the respondents and lastly, Forward Stepwise Regression Analysiswas employed to find out which of these predictors mostly influence the commission of errors. 


\section{RESULTS}

The data and information gathered pertinent to the questions raised in the study are presented in this chapter.

\section{Problem 1. What are the predictors in the commission of errors on nursing procedure in the ward in terms of knowledge skills and attitude?}

\section{On Knowledge}

As a result, on these, the grand mean of knowledge for the respondents is 4.07 with the verbal description of "often".

The findings suggest that the more the student nurses is able to acquire health information from the patient's condition, they are less likely to commit errors in the nursing procedures. Being a student nurse, he/she should be equipped with enough knowledge to take an active role in rendering the actual nursing care to the patients. As cited by Potter et al., 1990 knowledge is necessary to have a clear perception of the truth and the fact in the art of care giving. It is acquired by seeking information from experts in the field and through experience. Without this process, the health personnel have to review the procedure every time it is performed. The findings also suggest that commission of errors can highly be preventable if the student nurses will be able to formulate health teaching programs necessary for the patients care.

\section{On Skills}

Predictors in terms of skills have a total grand mean of 4.14 with a verbal description of "often". The findings imply that the mastery of skills require more than the mental assimilation of how something is to be performed. Although some individuals already have developed the skill, there are still some who need their skills to be enhanced. Hence, reinforcement while practicing helps strengthen the desired skill. If student nurses have the satisfactory skill in performing admission and routine procedures in the ward, they are less likely to commit errors or never at all.

\section{On Attitudes}

Attitude got a grand mean of 4.23 represented by a verbal description of "often". This means that the need to provide tender loving care is the primary goal a student nurse must have in mind to provide quality nursing care to every patient. Moreover, they must always know that patients are vulnerable in physical and emotional aspects.

\section{On Knowledge, Skills and Attitudes}

Data reveals that among the predictors, attitude got the highest mean of 4.23 which means that as student nurses, they should not only be equipped with the adequate knowledge and satisfactory skills but of course they should manifest desirable attitudes for this is the basic of nursing service to provide tender loving care and execute a patient centred care towards the patients. Data also shows an overall mean of 4.14 which means often that implies that student nurses is not totally equipped with enough knowledge, skills and attitudes thus the prevalence of committing errors in the nursing procedure in the ward is still present however it is minimal.

The findings mean that knowledge, skills and attitude as determinants on the commission of errors all contributes on how the student nurses perform the nursing procedures in the ward. Knowledge is important on how the student nurses understands and comprehends the lesson learn during the theories they learned in their classroom. The result reveals that knowledge has an overall mean of 4.07 which is the lowest among the predictors which means that the students is far to render effective nursing care if they have adequately high knowledge. A skill on the other hand, is the applications of the knowledge learn. In the same way, student nurses must also be equipped with desirable attitudes.

The findings suggest that as a student nurse, they must be knowledgeable enough, must be fully aware, and they must be completely inform and updated regarding the present technological advancements in the field of nursing care services. Aside from it, they should hone their skills in performing vital nursing procedures for the advantage of their patients and their profession. Most importantly, they must acquire the good values and attitudes necessary of becoming a nurse. This study shows that knowledge, skills and attitudes go hand in hand in the performance of not just a nurse but especially as a student nurse for this will be their basis and somehow a means of evaluating their selves if they can be a good nurse in the future that is 
well equipped with the basic knowledge, skill and attitude.

Problem 2. What are the errors committed in the nursing procedure in terms of Admissionand RoutineProcedures

\section{On Admission Procedures}

Results on the errors committed through admission procedures shows that the respondents always assure that the admission of the patient to the health agency is as comfortable and free from trauma. Admission procedure has a grand mean 4.03 with a verbal description "often".

Table 1: Distribution and Verbal Description on the Commission of Error on Admission Procedure

\begin{tabular}{|l|c|c|c|c|c|c|}
\hline \multicolumn{1}{|c|}{ Admission Procedures } & CI & VD & Student & VD & Staff & VD \\
\hline $\begin{array}{l}\text { 1. Provides the necessary } \\
\text { equipment in assisting the } \\
\text { patient to get inside the } \\
\text { receiving area of the hospital }\end{array}$ & 3.86 & 0 & 3.81 & 0 & 4.19 & 0 \\
\hline $\begin{array}{l}\text { 2. Conducts an in depth- } \\
\text { assessment of the patient }\end{array}$ & 3.43 & $\mathrm{~S}$ & 3.85 & 0 & 4.25 & 0 \\
\hline $\begin{array}{l}\text { 3. Utilizes the effective skills } \\
\text { in eliciting data from the } \\
\text { patient }\end{array}$ & 3.5 & $\mathrm{~S}$ & 3.83 & 0 & 4.29 & 0 \\
\hline $\begin{array}{l}\text { 4. Records all relevant } \\
\text { information taken from the } \\
\text { patient to the chart }\end{array}$ & 3.76 & 0 & 4.15 & 0 & 4.41 & 0 \\
\hline $\begin{array}{l}\text { 5. Prepares the necessary } \\
\text { apparatus for the patient's } \\
\text { initial vital } \\
\text { Signs }\end{array}$ & 4.3 & 0 & 4.27 & 0 & 4.58 & $\mathrm{~A}$ \\
\hline \multicolumn{1}{|c|}{ Overall mean } & $\mathbf{3 . 7 7}$ & $\mathbf{0}$ & $\mathbf{3 . 9 8}$ & $\mathbf{0}$ & $\mathbf{4 . 3 4}$ & $\mathbf{0}$ \\
\hline \multicolumn{2}{|c|}{ Grand mean } & $\mathbf{4 . 0 3}$ & & Often \\
\hline
\end{tabular}

This implies that the respondents receive the patient in the same courteous manner that they would use to welcome a guest in their own home. Data shows that the respondents are accountable for the patient's comfort and wellness when he arrives revealing that the respondents are accountable for the patient's comfort and wellness when he/she arrives in the hospital.

\section{On Routine Procedures}

The result on the summation of the relationship between the predictors and the errors committed in the ward as to the routine procedures had an overall mean description of "often" which means that student nurses often perform the nursing procedures in the ward with adequate knowledge, skills and desirable attitude leading to less commission of errors in the ward.
Table 2: Summary of Mean Distribution and Verbal Description on the Commission of Errors in Routinely Procedures

\begin{tabular}{|l|c|c|}
\hline Routinary Procedures & Mean & Verbal Description \\
\hline Endorsement & 3.74 & Often \\
\hline Nursing Rounds & 4.27 & Often \\
\hline Administration of medication & 3.63 & Often \\
\hline Vital Signs Taking & 4.48 & Often \\
\hline Carrying Out Doctor's Order & 4.12 & Often \\
\hline Treatment & 3.99 & Often \\
\hline Recording and Charting & 3.58 & Often \\
\hline Overall Mean & $\mathbf{3 . 9 7}$ & Often \\
\hline
\end{tabular}

The findings suggest that student nurses must ensures that any information and health details about the patient should be endorsed properly to the receiving nurses on duty especially those patients needing special attentions and for closely monitoring.

Problem 3. Is there a significant relationship between the predictors and the errors committed in the ward?

The findings reveal that there is a significant relationship between the 3 predictors and the errors committed in the ward in terms of admission procedures as indicated by the computed $r$ value which is greater than the critical value. This implies that as the knowledge, skills, and attitude of the respondents increases, his/ her application of the proper admission procedure also increases and thereby decreasing the likelihood of commissions of errors.

Table 3: Relationship between the Predictors and the Commission of Errors in the Ward

\begin{tabular}{|l|c|c|c|l|}
\hline \multirow{2}{*}{ Predictors } & \multicolumn{2}{|c|}{ Admission Procedures } & \multirow{2}{*}{ Decision on Ho } & Conclusion \\
\cline { 2 - 5 } & $r$ & $P$ & & \\
\hline Knowledge & $0.953^{* *}$ & 0.000 & Reject & Significant \\
\hline Attitude & $0.972^{* *}$ & 0.000 & Reject & Significant \\
\hline Skills & $0.959^{* *}$ & 0.000 & Reject & Significant \\
\hline \multirow{2}{*}{ Predictors } & \multicolumn{2}{|c|}{ Routine Procedures } & Decision on & Conclusion \\
\cline { 2 - 4 } & $r$ & $P$ & Ho 1 & \\
\hline Knowledge & $0.961^{* *}$ & 0.001 & Reject & Significant \\
\hline Attitude & $0.972^{* *}$ & 0.000 & Reject & Significant \\
\hline Skills & $0.969^{* *}$ & 0.000 & Reject & Significant \\
\hline
\end{tabular}

**Correlation is significant at the 0.01 level (2-tailed) 
In terms of the proper application of routine procedures, it shows the result of the correlation between the identified predictors and the commission of errors. The findings reveal a significant relationship between the predictor variables and routine procedure as indicated by their negligible $P$-values.

As indicated by their correlation coefficients, the relationship is positive. Thus, the application of proper routinely procedures increases with the increased knowledge, skills and positive attitude of the respondents. Consequently, the increase on those predictors decreases the likelihood that a student may commit error. However, a student with low knowledge, poor skills and undesirable attitude will most likely commit errors otherwise.

Problem 4. Is there a significant difference in the ratings of the respondents on the commission of errors of nursing procedure in the ward?

The data show that there is a significant difference in the ratings of the respondents on the commission of errors of nursing procedure in the ward as to the admission procedures among the 3 respondents. As indicated by the negligible P-value, the null hypothesis of non-difference is rejected at the 0.01 level of significance.

The significant difference on the commission of errors in terms of admission procedure among the group of respondents can be attributed to the fact that the group of respondents have different level of education, expectations and experiences. The clinical instructors and staff nurses are more experienced in terms of clinical set up than the students than the students.

Furthermore, the data reveal a non- significant difference on the mean ratings of the respondents in terms of routine procedures in the ward as shown in the table. As indicated by their $P$-values that are all greater than 0.05 , the data could not provide sufficient evidence to reject the null hypothesis. Hence, the null hypothesis is accepted at the 0.05 level of significance.

Table 4: One-Way Analysis of Variance on the Significant Difference of Respondents Ratings as to the Admission Procedure

\begin{tabular}{|c|c|c|c|c|c|c|c|}
\hline \multirow{2}{*}{$\begin{array}{c}\text { Commission } \\
\text { of Errors }\end{array}$} & \multirow[t]{2}{*}{ Respondent } & \multirow[t]{2}{*}{$\mathbf{N}$} & \multirow[t]{2}{*}{ Mean } & \multicolumn{4}{|c|}{ One-Way ANOVA } \\
\hline & & & & $F$ & $P$ & $\begin{array}{c}\text { Decision } \\
\text { on } \mathrm{Ho}_{2}\end{array}$ & Conclusion \\
\hline \multirow{3}{*}{ Admission Procedures } & $\mathrm{CI}$ & 30 & 3.77 & \multirow{3}{*}{8.528} & \multirow{3}{*}{0.000} & \multirow{3}{*}{ Reject } & \multirow{3}{*}{ Significant } \\
\hline & Student & 200 & 3.98 & & & & \\
\hline & Staff Nurse & 100 & 4.34 & & & & \\
\hline \multirow{3}{*}{ Endorsement } & CI & 30 & 4.07 & \multirow{3}{*}{2.672} & \multirow{3}{*}{0.071} & \multirow{3}{*}{ Accept } & \multirow{3}{*}{ Not Significant } \\
\hline & Student & 200 & 4.07 & & & & \\
\hline & Staff Nurse & 100 & 3.81 & & & & \\
\hline \multirow{3}{*}{$\begin{array}{l}\text { Nursing } \\
\text { Rounds }\end{array}$} & $\mathrm{CI}$ & 30 & 4.22 & \multirow{3}{*}{1.289} & \multirow{3}{*}{0.277} & \multirow{3}{*}{ Accept } & \multirow{3}{*}{ Not Significant } \\
\hline & Student & 200 & 4.22 & & & & \\
\hline & Staff Nurse & 100 & 4.38 & & & & \\
\hline \multirow{3}{*}{$\begin{array}{c}\text { Administration } \\
\text { of } \\
\text { Medications }\end{array}$} & $\mathrm{CI}$ & 30 & 3.95 & \multirow{3}{*}{3.996} & \multirow{3}{*}{0.019} & \multirow{3}{*}{ Accept } & \multirow{3}{*}{ Not Significant } \\
\hline & Student & 200 & 3.41 & & & & \\
\hline & Staff Nurse & 100 & 3.55 & & & & \\
\hline \multirow{3}{*}{$\begin{array}{c}\text { Vital Signs } \\
\text { Taking }\end{array}$} & $\mathrm{CI}$ & 30 & 4.49 & \multirow{3}{*}{1.299} & \multirow{3}{*}{0.274} & \multirow{3}{*}{ Accept } & \multirow{3}{*}{ Not Significant } \\
\hline & Student & 200 & 4.41 & & & & \\
\hline & Staff Nurse & 100 & 4.56 & & & & \\
\hline
\end{tabular}




\begin{tabular}{|c|c|c|c|c|c|c|c|c|}
\hline \multirow{12}{*}{ 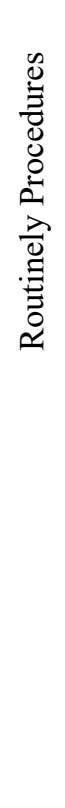 } & \multirow{3}{*}{$\begin{array}{c}\text { Carrying Out } \\
\text { Doctor's } \\
\text { Order }\end{array}$} & $\mathrm{CI}$ & 30 & 4.19 & \multirow{3}{*}{2.470} & \multirow{3}{*}{0.086} & \multirow{3}{*}{ Accept } & \multirow{3}{*}{ Not Significant } \\
\hline & & Student & 200 & 3.99 & & & & \\
\hline & & Staff Nurse & 100 & 4.22 & & & & \\
\hline & \multirow{3}{*}{ Treatment } & CI & 30 & 4.15 & \multirow{3}{*}{1.257} & \multirow{3}{*}{0.286} & \multirow{3}{*}{ Accept } & \multirow{3}{*}{ Not Significant } \\
\hline & & Student & 200 & 3.90 & & & & \\
\hline & & Staff Nurse & 100 & 4.04 & & & & \\
\hline & Recording and & $\mathrm{CI}$ & 30 & 3.82 & \multirow{3}{*}{2.422} & \multirow{3}{*}{0.090} & \multirow{3}{*}{ Accept } & \multirow{3}{*}{ Not Significant } \\
\hline & \multirow[t]{2}{*}{ Chatting } & Student & 200 & 3.41 & & & & \\
\hline & & Staff Nurse & 100 & 3.55 & & & & \\
\hline & Routinary & $\mathrm{CI}$ & 30 & 4.13 & \multirow{3}{*}{0.957} & \multirow{3}{*}{0.385} & \multirow{3}{*}{ Accept } & \multirow{3}{*}{ Not Significant } \\
\hline & Procedures & Student & 200 & 3.92 & & & & \\
\hline & & $\begin{array}{l}\text { Staff } \\
\text { Nurse }\end{array}$ & 100 & 4.01 & & & & \\
\hline
\end{tabular}

This implies that, at $95 \%$ confidence level, there is no significant difference on the commission of error in terms of the routinely procedures in the ward among the group of respondents. This is due to the fact that routinely procedures have been constantly practiced by the respondents thus, they have unanimous responses.
Problem 5. Which of the predictors will influence the commission of errors in the ward?

It reveals that all predictor variables (knowledge, skills and attitude) are significant in the commission of errors in the admission procedures in the ward area as indicated by their negligible $P$-values.

Table 5: Forward Stepwise Regression Analysis showing the Influence of the Independent Variables on the Dependent Variables

\begin{tabular}{|c|c|c|c|c|c|c|c|c|}
\hline \multirow[t]{2}{*}{ Step } & \multirow{2}{*}{$\begin{array}{c}\text { Variables } \\
\text { Entered }\end{array}$} & \multirow[t]{2}{*}{$\boldsymbol{R}$} & \multirow[t]{2}{*}{$R^{2}$} & \multicolumn{2}{|c|}{ Coefficients } & \multicolumn{2}{|c|}{ ANOVA } & \multirow[t]{2}{*}{ Regression Equation } \\
\hline & & & & Constant & Beta & $\boldsymbol{F}$ & $\boldsymbol{P}$ & \\
\hline 1 & Knowledge & $0.953^{\mathrm{a}}$ & 0.908 & 0.660 & 0.953 & 3245.46 & 0.000 & $\mathrm{AP}=0.660+0.953 \mathrm{~K}$ \\
\hline 2 & Attitude & $0.972^{\mathrm{b}}$ & 0.946 & 0.114 & $\begin{array}{l}0.179 \\
0.798 \\
\end{array}$ & 2850.22 & 0.000 & $\mathrm{AP}=0.114+0.179 \mathrm{~K}+0.798 \mathrm{~A}$ \\
\hline 3 & Skills & $0.974^{\mathrm{c}}$ & 0.948 & 0.006 & $\begin{array}{l}0.161 \\
0.605 \\
0.216 \\
\end{array}$ & 1981.94 & 0.000 & $\begin{array}{c}\mathrm{AP}=0.006+0.161 \mathrm{~K}+ \\
0.605 \mathrm{~A}+0.216 \mathrm{~S}\end{array}$ \\
\hline \multirow[t]{2}{*}{ Step } & Variables & $\mathbf{R}$ & $\mathbf{R}^{2}$ & \multicolumn{2}{|c|}{ Coefficients } & \multicolumn{2}{|c|}{ ANOVA } & Regression Equation \\
\hline & Entered & & & Constant & Beta & $\mathbf{F}$ & $\overline{\mathbf{P}}$ & \\
\hline 1 & Knowledge & $0.953^{\mathrm{a}}$ & 0.908 & 0.660 & 0.953 & 3245.46 & 0.000 & $\mathrm{AP}=0.660+0.953 \mathrm{~K}$ \\
\hline 2 & Attitude & $0.972^{\mathrm{b}}$ & 0.946 & 0.114 & $\begin{array}{l}0.179 \\
0.798 \\
\end{array}$ & 2850.22 & 0.000 & $\mathrm{AP}=0.114+0.179 \mathrm{~K}+0.798 \mathrm{~A}$ \\
\hline 3 & Skills & $0.974^{\mathrm{c}}$ & 0.948 & 0.006 & $\begin{array}{l}8.685 \\
0.216\end{array}$ & 1981.94 & 0.000 & $\begin{array}{c}\mathrm{AP}=0.006+0.161 \mathrm{~K}+ \\
0.605 \mathrm{~A}+0.216 \mathrm{~S}\end{array}$ \\
\hline
\end{tabular}


a. Predictors: (constant), knowledge

b. Predictors: (constant), knowledge, attitude

c. Predictors: (constant), knowledge, attitude, skills

d. Dependent Variable: Admission Procedure Routine Procedure

The result implies that the respondent's knowledge, skills and attitudes in the admission procedure determines the likelihood of committing errors. If the student nurses have high knowledge, skills and attitudes, the commission of errors is highly preventable and minimized. Otherwise, there will be a high risk of committing errors. It also reveals that attitude had the highest influence in the commission of errors in the nursing procedures in terms of admission and routine procedure as represented by their Beta Coefficient result of 0.798 . The finding means that as student nurses, having desirable attitude would mean less commission of error.

\section{Summary of Findings}

1. Predictors in the commission of errors revealed that all group of respondents are unanimous in their responses that the higher the knowledge, skills and desirable attitude the student had, the less likely to commit errors in the ward with a verbal description of "often". On the other hand, among the determinants of the commission of errors, attitude has the highest mean which reveals that attitude of student nurses mostly influence the commission.

2. In terms of admission and routine procedures, data reveals a homogeneous verbal description of "often" among the three groups of respondents.

3. Correlation between the predictors and the errors committed in the ward as to admission and routine procedure revealed that as indicated in their negligible $P$-values, it revealed a significant relationship between the commission of errors and the identified predictors.

4. One-way Analysis of Variance Test revealed that each rating of the respondents has a significant difference on the commission of errors in the ward. As to the admission procedure, data reveals that every respondent varies from their responses, this may bedue to the fact that respondents have different level of education, expectations and of course, level of experiences. On the other hand, in terms of the routinely procedures, there is no significant difference, maybe because this procedure has been constantly practiced by the respondents and they are already used to it.

5. Using the Forward Step-Wise method on the predictors that will influence the commission of errors in the ward in terms of the dependent variableAdmission and Routinary Procedure. Data revealed that all predictor variables are significant in the commission of errors as indicated by their negligible $P$ values. The respondents perceived that the higher the knowledge, skills and desirable attitude the student had, the less likely to commit errors in the ward. On the other hand, among the predictors in the commission of errors, data reveals that attitude has the highest influence in the commission of errors as represented by their beta coefficient on both admission and routine procedures.

\section{CONCLUSION}

Based on the findings generated from the study, conclusions are drawn. Because of the respondent's high knowledge, skills and attitude, commission of errors in the ward is prevented. The student nurses got a satisfactory performance in all nursing procedures that include admission and routine activities. If student nurses have the competence, the commission of errors is decreased. In the same way, if student nurses lack the knowledge, skills and attitude, the commission of errors in nursing procedures in the ward is high. For the admission procedure, there is a significant difference in the ratings of the respondents on the commission of errors of nursing procedure due to the fact that they belong to the different levels of education, experience and expectations. On the other hand, there is no significant difference in the ratings of the respondents on the commission of errors of nursing procedure in the ward for the routinely procedures maybe because the respondents are already used to the varied procedural details. The student nurses who have high competence less likely prevent errors. However, student nurses' attitude had mostly influenced the commission of errors.

\section{RECOMMENDATIONS}

The school administration should extend more support to the Nursing Program through financing the programs need such as budget assistance and should further develop effective plans for the betterment of the program and should aim high in producing competent 
nurses and should not be satisfied with average level. Student nurses should internalize the essence of the nursing profession and should show commitment, interest and dedication towards their course. They must be equipped with the satisfactory skills to render effective nursing care to their patients. At the same time, they should manifest desirable attitudes and implement nursing service with tender, loving care (TLC). They should put in mind that knowledge, skills and attitude should go hand in hand to effectively render care thus commission of errors should be minimized. Clinical Instructors should believe that teaching and learning process not only takes place in the classrooms but also in the clinical areas, and no students need not to be guided by them in their practice of the nursing procedures. It is necessary for the C.I. to develop and enhance the competence of the students holistically. The staff nurses should serve as a reminder to them that as partner in moulding the competence of the students, they should extend effort in correcting students' mistakes and share their resources through imparting knowledge to them. And lastly future researcher should conduct further research study related to the topic looking into the variables not included in the study.

\section{REFERENCES}

Catalano, J.T. (1991). Ethical and Legal Aspects of Nursing. Springhouse Corporation.

Chance, M. (2008). Horror Story at the Geriatic Floor: St. Luke's Medical Center. Victims of Medical Malpractice (Philippines).

Chinn, P.L. \& Jacobs, M.K. (1987). Theory and Nursing: A Systematic Approach. $2^{\text {nd }}$ edition. St. Louis: C.V. Mosby.

James, L.R., Demaree, R.G. \& Wolf, G. (1993). rwg: An assessment of within-group interrater agreement. Journal of Applied Psychology, 78(2), pp 306-309.

$\mathrm{Ju}, \mathrm{L}$. (2004). Factors Affecting the Commission of Errors among staff nurses and student affilliates in Medical Mission Group Hospital in Tagum City. Unpublished, pp 1-3.

Marriner-Tomey, A. \& Alligood, M.R. (2002). Nursing theorists and their work. St. Louis, Mo, Mosby.

Potter, P.A., Perry, A.G., Stockert, P. \& Hall, A. (1990). Fundamentals of Nursing. $2^{\text {nd }}$ Editiion. Lippincot Co.

Robles, G.S. \& Dionisio, A.B. (2001). Philippine Nursing Law, Jurisprudence and Ethics. Manila: Educational Publishing House.

Sitzman, K. \& Eichelberger, L.W. (2010). Understanding the work of Nurse Theorists: A creative beginning. $2^{\text {nd }}$ Edition. Sudbury, Massachusetts: Jones and Bartlett Publishers. 